\title{
Determinants of Smallholder Farmers' Participation in Pond Fish Production in Dara and Wonsho Districts, Sidama Zone, Southern Ethiopia
}

\author{
Tibebu Legese Mufato \\ Department of Agribusiness and Value Chain Management, Wolkite University, Wolkite, Ethiopia
}

Email address:

tibebu610@gmail.como

\section{To cite this article:}

Tibebu Legese Mufato. Determinants of Smallholder Farmers' Participation in Pond Fish Production in Dara and Wonsho Districts, Sidama Zone, Southern Ethiopia. Agriculture, Forestry and Fisheries. Vol. 10, No. 4, 2021, pp. 132-139. doi: 10.11648/j.aff.20211004.13

Received: May 29, 2021; Accepted: July 5, 2021; Published: July 13, 2021

\begin{abstract}
In developing countries like Ethiopia fish production plays a major role in food supply and poverty alleviation strategy. Despite the presence of opportunities to diversify fish production and thus maximize profit through product and market diversification, the farmers' participation in pond fish production in Dara and Wonsho districts is perceived to be generally very low. Therefore, this study analyzed the determinants of farmers' participation in pond fish production. Cross sectional research design and two stage-sampling techniques were implemented in this study. Both quantitative and qualitative data were collected from the primary and secondary sources. Descriptive statistics and econometric analysis were employed to analyze data. The result of the Heckman two stage model showed that pond fish production participation decision was significantly influenced by sex, adult family size, and total land, livestock ownership, annual farm income and frequency of the extension contact. Moreover, the level of pond fish production participation was influenced by age, land holding, annual farm income and credit use. Thus, it is suggested to strengthen smallholder farmers' participation in pond fish production via capacity improvement and enhanced access of proper technical support service provision.
\end{abstract}

Keywords: Fish Production, Heckman Two Stages, Participation, Pond, Smallholders

\section{Introduction}

Fisheries play an important role in the rural, national and global economy. The international trade in fish and fishery products has been growing day by day, the consumption of fish in Europe, America, Asia and other developing regions have been increasing which provides stimulus for the development of the fishery at international [20]. The global fish supply from fisheries was put at 167.2 million tones in 2014, with 146.3 million tones used for human consumption and providing an estimated apparent food fish per capita supply of about $20.1 \mathrm{~kg}$ (live weight equivalent); while the values were 1.72 million tones for Africa [12]. It is a veritable source of income and employment for over 284,000 fish farmers in Africa, and many more people engaged in fish processing and marketing [2].

Pond fish culture is specific segment of aquaculture that has always been closely linked to rural life and has inseparably combined the social, ecological and economic dimensions of fish production activity. These dimensions are collectively referred to as ecosystem services. Currently, there is particular need to take into consideration the multifunctionality of pond ecosystems [18].

Ethiopia has many lakes and reservoirs, small water bodies and floodplain areas covering a total surface area of about $14,794 \mathrm{~km}^{2}$ [5]. In the same way, Ethiopia has very diverse agro-ecological zones offering a favorable potential for developing fish culture, both in terms of land/water and in its climatic system. Based on GIS assisted modeling, about $15158 \mathrm{~km}^{2}$ and $871731 \mathrm{~km}^{2}$ of the total country's land, respectively, is high, moderately suitable for pond culture [16].

Even though the country has high potential and wide environmental condition for fish production, it was existing as small-scale, subsistence-oriented and only to a certain degree commercial (FAO, 2018). It is estimated that there are 
1300 subsistence fish farmers in Ethiopia with a pond size of about $100-400 \mathrm{~m}^{2}$ [2].

Small-scale pond fish aquaculture has been practiced in various parts of southern Ethiopia [21]. These ponds have an area ranging from $100-300 \mathrm{~m}^{2}$. Usually, fishponds are fertilized with poultry, cattle manure, and fishes feed with leftover food from livestock and agriculture. Nevertheless, theestablishment and expansion of small-scale pond fish production have been carried out regardless of the suitability of the in term of land, water socioeconomic and other inputs available pond aquaculture development [21].

Although the practice of pond fish production in Ethiopia has a century old history, the introduction and promotion of pond fish production culture to smallholder farmers is relatively recent phenomena [2]. With respect to effort exerted so far in pond fish production promotion in Ethiopia, the participation of smallholders is low. There are no sufficient studies conducted in the context of demographic, socioeconomic and institutional factors that could hinder or expedite the participation of smallholder farmers' in pond fish production. As a result, no information is available in line with such issues, and the determinant factors are not well identified and recognized. This holds true to Southern regional state and study areas where pond fish productions have been introduced to smallholder farmers [21].

Dara and Wonsho districts are potential fish producing areas in Sidama zone, southern Ethiopia. Despite the presence of opportunities to diversify fish production and thus maximize profit through product and market diversification, the smallholder farmers' participation in pond fish production is perceived to be generally very low. The total number of smallholder farmers engaged in fish production is only 75 smallholders in two districts [21]. Several studies conducted in the past have characterized fish production and reproduction in Ethiopia [19]. However, little researches were done on the determinants of smallholder farmers' participation in pond fish production. This shows the limitations of empirical evidence on the determinants of smallholder farmers' participation in pond fish production. Hence, this study was carried out to investigate the determinants of smallholder farmers' participation in a pond fish production.

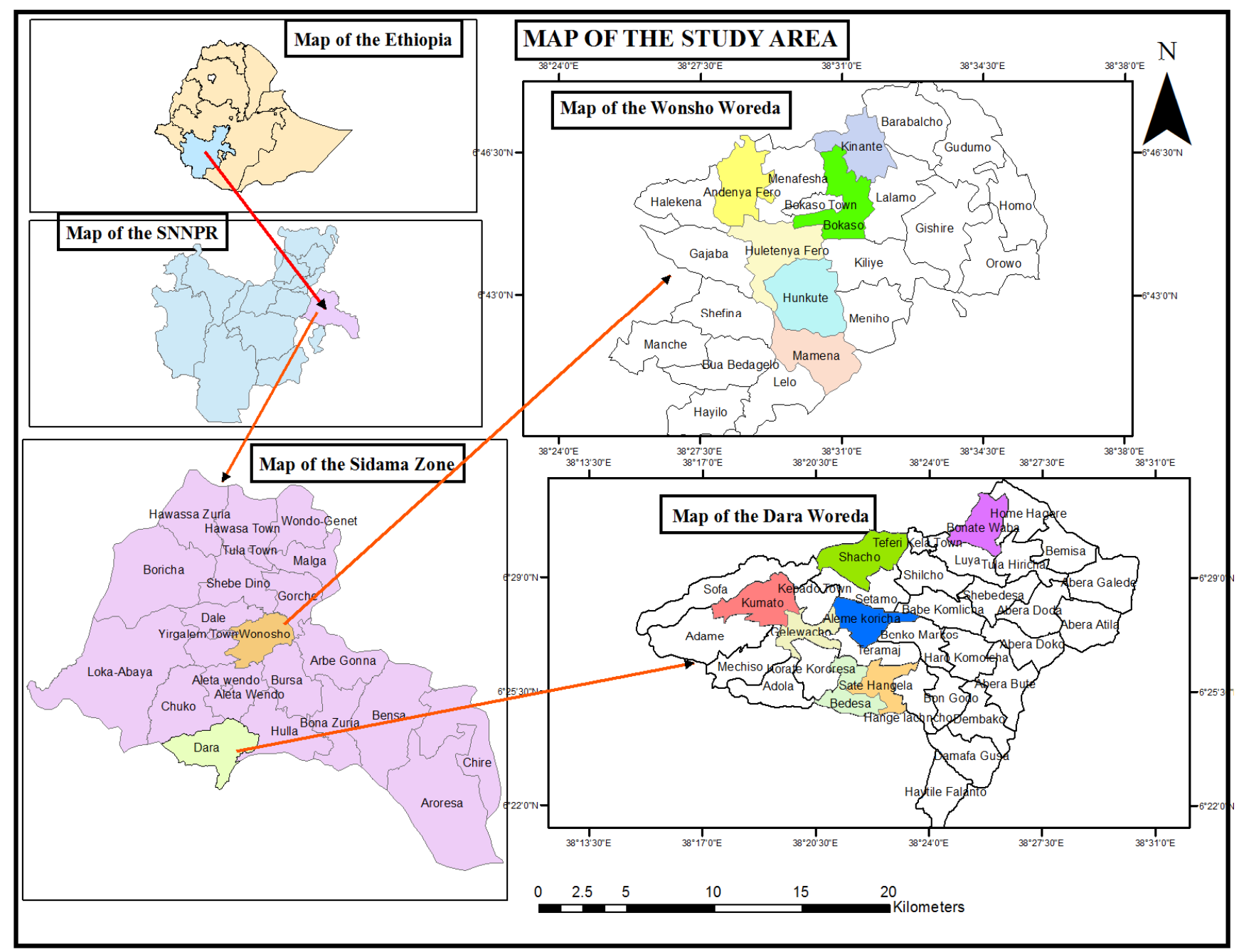

Source: GIS output, 2021

Figure 1. Map of the study areas. 


\section{Material and Methods}

\subsection{Description of Study Areas}

Wonsho district is located in the Sidama zone, southern Ethiopia. It shares boundaries with Aleta Wondo to the southwest, Shebedino on the North East, and Bursa on the southwest. Bokaso is the administrative town of Wonsho. It is located $330 \mathrm{~km}$ south of Addis Ababa and $57 \mathrm{Km}$ from south of Hawassa. The district comprises 23 Kebele administrations. Among these, three of them are urban Kebeles and 20 of them are rural Kebeles [10]. There are two agro climatic zones in the district, which is $(25 \%)$ Dega and (75\%) woyina-Dega. This district has a mean annual temperature between $10.1-20^{\circ} \mathrm{C}$ and mean annual rainfall between $1201-1600 \mathrm{~mm}$. The district is located between the elevations of 1001-350 masl [8]. It has an estimated total population 109,140 . Of these, 55,444 are male and the remaining 53,696 are female. In the district, more than $95 \%$ of the population earns their living from crop production and livestock and the rest 5\% earn living from petty trade and other livelihood activities. In the district potato sweet potato, coffee, inset/false banana/, barley, maize, chat are major cash crops in the area [11].

Dara district is located in Sidama zone, southern Ethiopia. Dara is bordered by

Gedeo zone on the south, Chuko on the North East, Aleta Wondo on the North and Hula on the North East. Kebado is the administrative town of Dara district. It is $345 \mathrm{~km}$ southwest of Addis Ababa and $85 \mathrm{~km}$ southwest of Hawassa. Administratively the District is divided into 33 rural and 7 urban Kebeles. The total population of Dara district is 209,886 , of which $102,215(48.7 \%$ ) are males and 107,671 $(51.3 \%)$ are females [10]. This district has a mean annual temperature between $12.6-22.5^{\circ} \mathrm{C}$ and the mean annual rainfall between $1201-1600 \mathrm{~mm}$. It is located between the elevations of 1501- 3000 masl [8]. In the district mixed agriculture (crop and livestock production) is practiced in the study area [11].

\subsection{Research Design}

The cross-sectional survey research design which is among the most commonly used non-experimental design was used for this study. In cross-sectional field surveys, independent and dependent variables are measured at the same point in time.

\subsection{Data Type and Sources}

Both quantitative and qualitative data were used for this study. In order to generate these data, both primary and secondary data sources were used. Primary data sources were randomly selected 75 fish farmers and 150 non-fish farmers and experts. Moreover key informant interview was employed by preparing questions. Secondary data sources include journals, annual reports, websites and different published and unpublished materials.

\subsection{Method of Data Collection}

Before data collection, the questionnaire was pre-tested on eight farmers to evaluate the appropriateness of the design and clarity of the questions, relevance of the questions and to estimate the time required for an interview. Subsequently, appropriate modifications and corrections were made on the protested questionnaires in order to capture the relevant information related to the study objectives. Four enumerators who completed a first degree and have knowledge of the local culture, and language of the community were employed to conduct the interview. They were given appropriate training including field practices, in order to make them understand the objectives of the study, the contents of the questionnaire, how to approach the respondents and conduct interview.

\subsection{Sampling Technique and Sample Size}

In order to select a representative sample for this study, a two- stage sampling technique was implemented. In the first stage with consultation of Districts fishery experts and development agents, out of total Kebeles of Dara and Wonsho districts fish producer Kebeles were identified, all fish producing Kebeles (8 Kebeles from Dara and 6 Kebeles from Wonsho) were selected purposefully. Secondly, sample consisting fish farmers and non-fish farmers were drawn. Since the number of farmers who were producing fish in each selected Kebeles was reasonably small, all fish farmers were selected while sample non- fish farmers were selected using simple random sampling technique (lottery method). In order to compare fish producers to non-producers two fish farmers per one fish farmer in the areas were selected. A total of 225 household head (75 fish farmers and 150 non-fish farmers) were interviewed in this study

\subsection{Method of Data Analysis}

Both descriptive and econometric analyses were used to analyze data. The STATA version 13 was used to analyze quantitative data.

\subsubsection{Descriptive Method of Analysis}

Descriptive Statistics such as frequency, mean, percentage and standard deviations were employed to compute and understand the various socioeconomic, demographic and institutional characteristics of household in the sample.

\subsubsection{Econometric Model Specification}

Based on the nature of the decision, the Heckman's twostage selection model whose estimation involves two stages was used to address the second objective of this study, particularly to analyze the determinants of the pond fish production participation and level of participation (pond size).

These two successive equations, namely selection equation and outcome equation, respectively, are presented as follows [24]. 


\section{Selection equation}

$$
\begin{aligned}
& y^{*} 1 i=x 1 i \beta 1+\varepsilon i ́ 1 i \\
& y 1 i=1, i f y^{*} 1 i>0, \\
& y 1 i=0, \text { if } y^{*} 1 i<0,
\end{aligned}
$$

Outcome equation

$$
\begin{gathered}
y^{*} 2 i=x 2 i \beta 2+\varepsilon i 2 i \\
y 2 i=y^{*} 2 i, \text { if } y^{*} 1 i>0,
\end{gathered}
$$

$y 2 i$ Isnot observed if $y^{*} 1 i<0$

Where,

$y 1 i=$ probability of participation in pond fish production $y 2 i=$ level of participation/ pond size/

$x^{\prime} s=$ independent variables/ household characteristic's

$\varepsilon_{i^{-}}=$error term

The first stage of the model which assessed the decision to participate or not, whereas in the second stage OLS was used to analyze the level of participation [24], The reason behind the two-stage approach is that the decision on the level of production (pond size) is usually preceded by a decision to engage in the process of pond fish production

\subsection{Definitions and Hypothesis}

\subsubsection{Dependent Variable}

Pond fish Production participation decisions: Limited dependent variable taking value of " 1 " if the farmers participated in pond fish production and " 0 " otherwise. It is used to identify the factors determining the pond fish production participation decisions

Level of pond fish production participation: In this study, it represents the pond size. It is continuous variable and measured in meter square and it is used as the dependent variable to analyze factors that influence the level to which farmers decide to produce fish.

\subsubsection{Explanatory Variables}

Based on empirical studies conducted before, the following explanatory variables were hypothesized to affect pond fish production participation level of farmers and summarized in Table 1.

Table 1. Descriptions of explanatory variables specified in the models and their expected signs.

\begin{tabular}{ll}
\hline Dependent variable & \\
\hline $\begin{array}{l}\text { Probit Model ( } 1 \text { = pond fish production participant, } 0=\text { non participant) } \\
\text { Truncated Model (it represents the pond size in meter square. }\end{array}$ & Expected sign \\
Independent Variables & \\
Sex of household head ( 1 if male, 0 otherwise & positive /negative \\
Farmers age (years) & negative \\
Family size (ADE) & Positive \\
Education (year of schooling) & positive \\
Land size (ha) & positive \\
Farming experience (years) & positive \\
Number of livestock (TLU) & positive \\
Farm income (Birrs) & positive \\
Participation in nonfarm $(1$ if yes, 0 otherwise $)$ & Positive /negative \\
Distance to nearest market $(K M)$ & negative \\
Frequency of extension contact (days) & positive \\
Access to credit service (discrete) & positive \\
\hline
\end{tabular}

Source: Literature reviewed.

\section{Result and Discussion}

\subsection{Characteristics of Sample Households}

Households' likelihood of participation in pond fish production was found to be different among respondents with different socioeconomic, demographic and institutional characteristics. Table 2 shows the characteristics of sample households with continuous and discrete variables tested using t-test and Pearson chi-square test, respectively.

As indicated in Table 2, the mean age of fish farmers and non-fish farmers in years was 39.4 and 43.9 respectively. The result shows, as it was expected, younger farmers were more participating in fish production than elderly farmers were. The t-test (2.67) result indicates that, there was statistically significant difference between the mean age of fish farmers and non-fish farmers at $1 \%$ significance level.

The mean adult equivalent unit for fish farmers and nonfish farmers was 3.5 and 3.4 respectively. The t-test $(-0.83)$ shows that, there was no statistically difference among fish farmers and non-fish farmers in terms of mean adult family size.

The mean farming experience of fish farmers and non-fish farmers in years was 24.7 and 21.7 years respectively. There was a statistical significant difference between two groups, namely fish farmers and non-fish farmers at $1 \%$ probability level (t-value -3.08) on mean farming experience. Concerning to the educational status of household, the mean schooling years for fish farmers and non-fish farmers were 4.98 and 3.91 respectively. Educational status of fish farmers was not statistically different from non-fish farmers (tvalue $=-1.43)$ (Table 2). 
The mean land holding in hectare for fish farmers and nonfish farmers were 1.3 and 1.02 hectare respectively. The t-test $(-3.9)$ shows that, there was statistically significant difference between fish farmers and non-fish farmers in mean land holding. The result shows existence of association between land holding and fish production. Regarding to livestock ownership of household, the mean livestock ownership in TLU of sample fish farmers and non-fish farmers was 4.4 and 3.8 TLU with a standard deviation of 1.51 and 1.52 respectively. The t-test value shows there was a difference in mean livestock holding between fish farmers and non-fish farmers (t-value, -2.94).

The mean annual income of fish farmers and non-fish farmers were 9533 and 6008 ETB respectively. As shown in Table 2, there was statistically significant mean annual income difference between fish farmers and non-fish farmers $(\mathrm{t}$-value $=-7.16)$.

The mean extension contact for fish farmers and non-fish farmers was 9.49 and 5.86 days respectively. The t-test value showed that there was a significant difference in mean extension contact $(\mathrm{t}=-6.13)$ between fish farmers and non-fish farmers. Regarding to distance from the nearest market at $5.11 \mathrm{~km}$ distances for fish farmers whereas non-fish farmers were about $7.35 \mathrm{~km}$ far away from the nearest market. As ttest (-7.67) value indicated that there was statistically significant mean distance difference in $\mathrm{km}$ between fish farmers and non-fish farmers from their homestead to the nearest market to homestead at $1 \%$ significance level.

The result of survey showed that, out of fish farmers $93.3 \%$ were male while only 6.7 of them were male. Out of the non-fish farmers $78.7 \%$ were male while only $21.3 \%$ were female. The chi-square test showed that there was a statistically significant difference $\left(\chi^{2}=7.828, p=0.005\right)$ between sex of households.

The survey result also showed that $70.7 \%$ of the fish farmers and $57.3 \%$ of the non-farmers had access to credit. The chi-square test $\left(\chi^{2}=15.705\right)$ showed that, there was a statistical difference in access to credit between fish farmers and non-fish farmers in terms

Moreover, survey result indicated that $65.3 \%$ of fish farmers participated in non-farm whereas $34.7 \%$ participated in off/non-farm. $66.7 \%$ of non-fish farmers participated in non-farm while $33.3 \%$ of them were not. The chi-square test $\left(\chi^{2}=0.81\right)$ showed that, there was no statistical significant difference between fish farmers and non- fish farmers in term of the participation in nonfarm activities.

Table 2. Summary statistics, mean comparison and proportion test (chi-square test) among Pond fish production participant and non-participant.

\begin{tabular}{|c|c|c|c|}
\hline \multirow{2}{*}{$\begin{array}{l}\text { Total number of observation (225) } \\
\text { Continuous variable }\end{array}$} & \multirow{2}{*}{$\begin{array}{l}\text { Fish farmers (75) } \\
\text { Mean }\end{array}$} & \multicolumn{2}{|c|}{ Non fish farmers (150) T-value } \\
\hline & & Mean & \\
\hline Age (years) & 39.4 & 43.9 & $2.67 * * *$ \\
\hline Family size (ADE) & 3.5 & 3.4 & -0.83 \\
\hline Farming experience (years & 24.7 & 21.7 & $-3.08 * * *$ \\
\hline Education (year of schooling) & 4.98 & 4.19 & -1.43 \\
\hline Total land size (hectares) & 1.3 & 1.02 & $-3.9 * * *$ \\
\hline Farm income (ETB) & 9533 & 6008 & $-7.73 * * *$ \\
\hline Extension contact (days) & 9.49 & 5.86 & $6.13 * * *$ \\
\hline Distance to market $(\mathrm{km})$ & 5.11 & 7.35 & $7.67 * * *$ \\
\hline Dummy variable & Percentage & percentage & Chi-square \\
\hline Sex (male \%) & 93.3 & 78.7 & $7.828 * * *$ \\
\hline Credit service (yes \%) & 70.7 & 57.3 & $15.705 * * *$ \\
\hline Part in non-farm activities (yes \%) & 65.3 & 66.7 & 0.81 \\
\hline
\end{tabular}

Source: own survey data (2021), *** significant at the 1\% significance level

\subsection{Econometric Result}

The result of the two stage Heckman model for the participation decision and level of participation revealed that the coefficient of Mills ration (Lambda) is significant at the probability of 5\%. Moreover, the model's goodness of fit and likelihood function were significant at Walda $\operatorname{chi}^{2}(11)=$ $133.62(\mathrm{p}=0000)$.

The finding assures the appropriateness of the two-stage Heckman model to avoid sample selection bias could have been experienced because of the existence of unobservable farmer characteristics determining the farmers' likelihood to participate in pond fish production and thereby affecting the level of participation. The result of Heckman two stage models is discussed separately under the following subsections in detail.

\section{1) Determinants of participation in pond fish production}

Several variables were hypothesized to influence farmers' participation in pond fish production in the study areas. Table 3 below show variables influencing farmers' participation in pond fish production

Sex of household head: Sex of the household head was found to be directly and significantly related at $1 \%$ probability level with the probability of the participation in pond fish production. The marginal effect result implied, other things remain constant, male-headed households were $40.1 \%$ more likely participating in pond fish production in comparison to female-headed households. Beyene [7], investigated the determinants of agricultural production participation decisions of farm households in Ethiopia and 
found that women were less likely to participate in agricultural production because of the influence of the head and cultural factors that females are naturally assigned to household activities.

Table 3. Result of first stage Heckman selection (probit) estimation of determinants of participation probability in pond fish production.

\begin{tabular}{|c|c|c|c|c|}
\hline Variable & Coefficient & Std. Error & t- value & marginal effect \\
\hline Sex of household head (male $=1$ ) & 2.883 & 0.9781 & -2.97 & $0.401 * * *$ \\
\hline Age of the household head (years) & -0.103 & 0.029 & 2.43 & $-0.024 * * *$ \\
\hline Family size of household head $(A D E)$ & 0.078 & 0.157 & 0.50 & 0.018 \\
\hline Educational status (formal schooling) & -0.05 & 0.079 & 0.476 & -0.013 \\
\hline Total land of household head (hectare) & 1.078 & 0.369 & 2.37 & $0.260 * * *$ \\
\hline Farming experience of household (years) & -0.006 & 0.041 & 0.863 & -0.001 \\
\hline Total farm income of household (ETB) & 0.003 & 0.0001 & 3.20 & $0.0006^{* * *}$ \\
\hline Participation in off/non-farm (yes=1) & -0.388 & 0.562 & 0.490 & -0.0095 \\
\hline Frequency of extension contact (Days) & 0.329 & 0.094 & -3.16 & $0.079 * * *$ \\
\hline Distance to the nearest market $(K M)$ & 0.095 & 0.077 & 0.221 & 0.023 \\
\hline Credit use of household (yes $=1$ ) & 0.159 & 0.915 & 0.861 & 0.0364 \\
\hline -Cons & 3.615 & 1.909 & 0.058 & \\
\hline Number observation & 225 & & & \\
\hline Uncensored observation & 75 & & & \\
\hline Wald $\mathrm{chi}^{2}(11)=133.62(0.000) * * *$ & rho $=1$ & & Sigma $=355.8092$ & \\
\hline
\end{tabular}

Source: own survey data (2021.) $* * *, * *$ significantly different at $1 \%$ and $5 \%$, respectively.

Age of the household head: Age of the household affected positively the probability of participation of smallholder farmers in pond fish production at $1 \%$ probability level. The result of marginal effect indicated that ceteris paribus, older farmers were $2.4 \%$ less likely to participate in pond fish production in comparison with younger farmers. The finding of the study is in consonance with that of [22], who reported that young people are keen to participate in new technologies

Land size of the household head: Land size of the household head was found to be directly and significantly related to probability of participation in pond fish production at $1 \%$ probability level. As the land size of the household increase by one unit, the probability of the participation of smallholder farmers in pond fish production increase by $26 \%$. This implies, as land size increases farmers would tend to be commercially oriented due to larger farm sizes. [3] Who also found that available land and the presence of other resources increase activities on the farm, supported this finding

Livestock ownership of household: Livestock holding was found to be directly and significantly related at $5 \%$ probability level with the probability of participation in pond fish production. The result of the marginal effect indicated that, keeping other independent variables in constant, as the livestock ownership increased by one unit, the probability of the participation in pond fish production increased by $8.4 \%$. [23], found that livestock holding has an influence on the adoption of new maize variety technology reported the same results.

Income of the household head: Income of the household head was found to be significantly and positively influences pond fish production participation at $1 \%$ significance level. The marginal effect result revealed that, keeping other exogenous variable at their mean level, as farmers' income increase by one Ethiopian birr the probability of participation in pond fish production increase by $0.06 \%$ [14], showed a like relationship between annual family income of respondent farmers and their adoption of aquaculture technologies

Frequency of extension contact: As hypothesized, frequency of extension contact affected positively and significantly the probability of participation in pond fish production at $1 \%$ significance level. The result of marginal effect indicated that ceteris paribus, when the frequency of extension per year increases by one day, the probability of participation of smallholder farmers in pond fish production also increases by $7.9 \%$. This finding is in consonance with that of [4]. The result indicated that individuals who have access to extensive contact have a greater likelihood of participation in new agricultural technology than those who cannot access to extension contact

2) Determinants of the level of pond fish production participation decision

In the second stage, age of the household head was negatively associated and statistically significant with the level of participation at the $1 \%$ level of significance. On the other hand, land size of the household, farm income and credit use of the household influenced the pond size for fish production positively at $5 \%$ level of significance.

Age of the household head: This variable was found to be influenced the level of participation positively by $1 \%$ and its effect was as expected on the hypothesis. Survey result indicated as the age of the producers increase by one year, the size fishpond declines by $188.64 \mathrm{~m}^{2}$. The result shows older farmers were less likely allocate more pond fish farm land when compared with younger farmers. The finding supported by [6], indicated that the age of the household head negatively affected the mean proportion of land allocated to 
improved wheat varieties.

Land size of the household head: Land size of the household head was found affects the level of participation in pond fish production at 5\% significance level. Keeping other variable at constant, as the landholding of the household increase by one hectare, the fishpond size increases by 227.3 $\mathrm{m}^{2}$. Farmers with a higher land holding size, allocate more land for pond fish production than those with a lesser land size. The result is in consistence with [9], who revealed that the total land owned showed land holding of the household significantly and positively influenced farmers cultivating different types of maize varieties.

Table 4. Result of selection estimation of determinants of level of participation in pond fish production.

\begin{tabular}{lll}
\hline Variable & Coefficient & Std. Error \\
\hline Sex of household head (male=1) & 64.556 & 220.655 \\
Age of the household head (years) & $-188.64 * * *$ & 35.879 \\
Family size of household head $($ ADAE) & 29.05 & 21.82 \\
Educational level (year of schooling & 46.6 & 48.7 \\
Land size of household head (years) & $227.3 * *$ & 85.1 \\
Farming experience of the household & -9.15 & 6.60 \\
Livestock ownership (TLU) & -0.001 & 0.002 \\
Total farm income of household (ETB) & $269.082 * *$ & 121.7 \\
Participation in off/non-farm (yes $=1)$ & 0.003 & 0.004 \\
Frequency of extension contact (Days) & -0.112 & 0.217 \\
Credit use of household (yes $=1)$ & $135.58 * *$ & 84.3 \\
-Cons & -174.9 & 683.3 \\
Mils lambda & $0.931 * *$ & 0.373 \\
Number observation & 225 & 0.425 \\
Censored observation & 150 & 0.314 \\
Uncensored observation & 75 & -5.14 \\
Wald chi $(11)=133.62(0.000) * * *$ & rho $=1$ & 0.957 \\
\hline
\end{tabular}

Source: own survey data (2021.) $* * *, * *$ significantly different at $1 \%$ and $5 \%$, respectively

Annual farm income: Amount of farm income affects the fishpond size that fish farmers had at 5\%. As shown in the model result coefficient, an increase in the household's farm income by one Ethiopian Birr, the fishpond size for fish production increases by $269.082 \mathrm{~m}^{2}$. This might be due to farmers' ability to afford inputs for pond fish production because of farm income. The result is in line with [1], who found that annual farm income significantly and positively influenced the area of land allocated to improved maize

Credit use: This variable was found to be affected fishpond size at $5 \%$ significance level. The result of this study indicated, as a producer is credit user, his/her pond fish size for fish production would higher by $135.58 \mathrm{~m}^{2}$. This may, as farmers use credit they expected to purchase different farm inputs than non- users and thus can allocate more land for fish production. [1], supports the finding of the current study by arguing for agricultural credit as it plays a vital role in the process of smallholder commercialization

\section{Conclusion and Policy Implications}

In spite of the advantages, not all farmers are taking part in pond fish production. Sex of the household, family size, total land size of the household, livestock ownership, annual farm income and frequency of the extension contact were seemed to influence smallholder farmers' participation decision in pond fish production. Besides, result also revealed that once a small holder farmer decides to participate in pond fish production, age of the household head, total land holding and credit use were important factors that significantly affectected the level of participation in pond fish production (pond size). Thus, it is recommended that the governmental organization such as districts office of fishery and livestock and nongovernmental organizations have to enhance knowledge and skills of smallholders to participate in pond fish production, through provision of technical assistance and training service to farmers.

\section{Competing Interests}

The authors declare that they have no competing interests.
Abbreviations
CSA
DOFEDO
Central Statistical Agency
$\begin{array}{ll}\text { DOA } & \text { Development } \\ \text { ETB } & \text { District Office of Agriculture } \\ \text { Ethiopian Birr }\end{array}$
FAO
GIS
MASL
OLS
SELFB
TLU
Food and Agriculture Organization
Global Information System
Meter above Sea Level
Ordinary Least Square
Southern Ethiopia Livestock and Fishery Bureau
Tropical Livestock Unit

\section{References}

[1] Abdissa G, Girma A., H Verkuijl and W. Mwangi, 2001. Farmers' Maize Seed Systems in Western Oromia, Ethiopia. International Maize and Wheat Improvement Center (CIMMYT) and Ethiopian Agricultural Research Organization (EARO). Mexico. p. 20. 
[2] Abera, L. 2017. Fisheries Production system scenario in Ethiopia. International journal $J$ of Fisheries and Aquatic Studies. 5 (1): 79-84.

[3] Anim, F. D. K. 2011. Factors Affecting Rural Household Farm labour Supply in Farming Communities of South Africae, Journal of Human Ecology, 34 (1), pp. 23-28.

[4] Arega, D. A., Manyong, V. M., Omanya, G., Mignouna, H. D., Bokanga, M. \&Odhiambo, G. 2008. Smallholder Market Participation under Transactions costs: Maize Supply and Fertilizer Demand in Kenya. Food Policy, 33, 318-328. https://doi.org/10.1016/j.foodpol.2007.12.001

[5] Assefa, M. J. (2014). Research Journal of Agriculture and Environmental Management, 3 (9): 460-466, September 2014.

[6] Bekele Hunde, Kotu H. Verkuijl, W. Mwangi and D. Tanner, 2000. Adoption of Improved Wheat Technologies in Adaba and DodolaWoredas of the Bale Highlands, Ethiopia. Mexico, International Maize and Wheat Improvement Center (CIMMYT) and Ethiopian Agricultural Research Organization (EARO).

[7] Beyene, A. D, 2008 "Determinants of off-farm participation decision of farm households in Ethiopia”, Agrekon, 47 (1). pp. 140-161.

[8] Central Statistical Agency of Ethiopia, Addis Ababa. Central Statistical Agency. 2010. Area and Production of Major Crops. Sample Enumeration Survey. Addis Ababa, Ethiopia.

[9] Dawit, T., W. Neil Adger, K. Brown and M. Badjeck. 2008.

[10] DOFED (Districts Office Finance and Economic Development) office report, 2019.

[11] DOA (Districts office of Agriculture) annual report, 2021.

[12] F. A. O (Food and Agriculture Organization), 2016. Rome, Italy. Promoting the Growth and development of Smallholder Seed Enterprises for Food Security Crops.

[13] FAO (Food and Agriculture Organization), 2018. Meeting the sustainable development goals. Rome.

[14] Go swami, B., G. Ziauddin and S. N. Data, 2010. Adoption Behavior of Fish Farmers in Relation to Scientific Fish
Culture Practices in West Bengal. Indian Research Journal of Extension Education, 10 (1): 24-28.

[15] Gujarati, D. N., 2003. Basic Econometrics. 4th Edition. McGraw Hill, New York. Pp. 563-636.

[16] Habtesilassie, R, 2012. Fishes of Ethiopia: annotated checklist with pictorial identification guide. P. 250. Office for Development Cooperation of Austrian Embassy, Addis Ababa, Ethiopia.

[17] Haji Biru, 2003. Adoption of crossbred dairy cows in Aris Zone, The case of Tiyo and LemuBilbilo Woreda. AM. Sc. Thesis presented to School of Graduate Studies of HaramayaUniversity.

[18] Landuyt, Pieter Lemmens, Rob Dhondt, Steven Broekx. 2014. et al., DAn Ecosystem Service Approach to Support Integrated Pond Management: A Case Study Using Bayesian Belief Networks-Highlighting Opportunities and Risks.

[19] Natea, G., Wakjira, M., Negisho, T. and Endebu, M, 2017. Spawning response of African catfish (Clarias gariepinus (Burchell 1822), Claridae: Teleost) exposed to different piscine pituitary and synthetic hormone. International journal of Fisheries and Aquatic Studies. 5 (2): 264-269.

[20] Shinog et al., 2009. Export of India's Fish and Fishery Products: Analyzing the Changing Pattern/Composition and Underlying Causes.

[21] Southern Ethiopia Livestock and fishery bureau annual report, 2018.

[22] Tenge, A, J., Graaff, J. D. \&Hella, J. P. (2004). Social and economic factors affecting the adoption of soil and water conservation in West Usambara highlands, Tanzania. Land Degradation and Development, 15 (2), 99-114. https://doi. org/10.1002/ldr.606.

[23] Tesfay Zenebe and Alemu Haileye, 2001. Adoption of improved maize technologies and inorganic fertilizer in Northwestern Ethiopia. Ethiopian Agricultural Research Organization (EARO). Research report No. 40, Addis Ababa, Ethiopia. $51 \mathrm{p}$.

[24] Wooldridge, J., 2002. Econometric analysis of cross section and panel data. MT press, USA. 